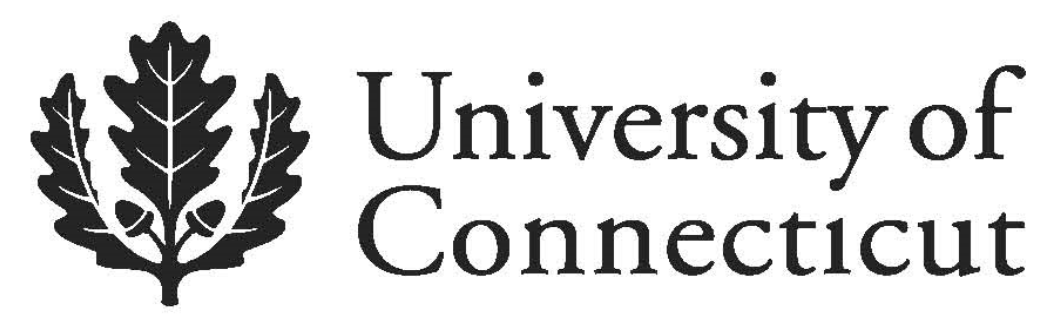

Department of Economics Working Paper Series

Efficiency of College Education in the Labor Market of the United States

William Alpert

University of Connecticut

Alexander Vaninsky

Hostos Community College of the City University of New York

Working Paper 2013-22

August 2013

365 Fairfield Way, Unit 1063

Storrs, CT 06269-1063

Phone: (860) 486-3022

Fax: (860) 486-4463

http://www.econ.uconn.edu/

This working paper is indexed on RePEc, http://repec.org 


\title{
Efficiency of College Education in the Labor Market of the United States
}

\section{William Alpert ${ }^{\mathrm{a}}$}

\author{
Alexander Vaninsky ${ }^{\mathrm{b}, \mathrm{c}}$
}

a. University of Connecticut, Stamford. One University Place, Stamford, CT, 06901, USA. E-mail: alpert@uconn.edu. Tel.: 1-203-251-8413.

b. Hostos Community College of The City University of New York. 500 Grand Concourse Avenue, Bronx, NY 10451, USA. E-mail: avaninsky@hostos.cuny.edu. Tel.: 1-718-3197930.

c. Corresponding author. 


\begin{abstract}
The paper discusses the worthiness of the resources allocated for college education from the point of view of their value in the labor market. We use Data Envelopment Analysis (DEA) to weigh the share of GDP spent on a college education and weighted time of labor force college study against productivity, employment rate, and labor force participation. Based on the data of the United States labor market for the period of 1980 - 2010, we received that the efficiency of a college education had no statistically significant tendency to increase or decrease over the period of the research but was closely related to the business cycles with a lag of one year.
\end{abstract}

Keywords: College education; Efficiency; Labor force productivity; Employment rate; Labor force participation; Data Envelopment Analysis 


\section{Introduction}

There is a growing evidence in the American society that college education is on average no longer worth what it costs. The historical rate of return to a 4 year college degree has seldom been estimated at less than 7 percent and has throughout the last 2 decades of the last century remaind at about 10 percent. However, these returns have fallen for most demographic groups according to recent work by Brown et al. [3] "....indicates that the gains from college education were flat in the 1980s and actually decreased significantly in 1991-2007 period. On the other hand, the gains to a high school education have increased quite dramatically over time. We also show that both high school and college education help to decrease the gender gap in life-time earnings, contrary again to the conclusion from wage premia calculations."

Further, it has been well established (and undisputed to this writing) that workers with more years of formal schooling have lower risk of unemployment and shorter durations of unemployment than workers with more schooling, Mincer [17]. In addition, among the recent evidence, the monograph of Bennett and Wilezol [2]. It states that the cost of attending a college or university has risen for timed the inflation rate since 1990, and by 2016 the cost of attending college will double compared with 2000 . Also, the pay to college graduates has fallen by $5 \%$ since 2007-2008. One of the reasons, as the authors state, is the government policy of making the college loans easily available: The total has exceeded a trillion dollars as far as now. Another reason is the increase in the overhead. Colleges are overloaded with staff and services that are not directly related to the educational process. This observation has been made as well. In 1976, the ratio staff/faculty was $0.5 / 1$, now it is $1: 1$. In particular, the median pay for the public-college presidents exceeded $\$ 440$ thousand, with some of them taking home above $\$ 1$ million.

In line with these observations is article [21] stating that from 1980 through 2011 the cost of university education has risen from $20 \%$ to $44 \%$ (Table 1) of median household income, and only $57 \%$ of students complete the four-year program in six years. In the inflation-adjusted terms, the college graduate made the same money in 2007 as in 1979. However, American education, as this article mentions, is not in very bad shape. More than 50\% of the top 100 universities and $80 \%$ of top 10 are American. They produce most of the scientific papers and Nobel Prize laureates. And college graduates still make more than hose without the degree. Source for information in the above paragraphs: http://www.economist.com/node/21559936 
TABLE 1

\begin{tabular}{|c|c|c|c|}
\hline & COST OF 4 YEAR INSTITUTION & MEDIAN & COLLGE \\
\hline & & HOUSEHOLD & COST AS \\
\hline Column 1 & Column 2 & INCOME & \% OF INCOME \\
\hline $2010-11$ & 22,092 & Column 3 & Column 4(=2/3) \\
\hline $2009-10$ & 21,093 & $\$ 50,054$ & $44 \%$ \\
\hline $2008-09$ & 20,409 & $\$ 49,277$ & $43 \%$ \\
\hline $2007-08$ & 19,363 & $\$ 49,777$ & $41 \%$ \\
\hline $2006-07$ & 18,471 & $\$ 50,303$ & $38 \%$ \\
\hline $2005-06$ & 17,451 & $\$ 50,233$ & $37 \%$ \\
\hline $2004-05$ & 16,510 & $\$ 48,201$ & $36 \%$ \\
\hline $2003-04$ & 15,505 & $\$ 46,326$ & $36 \%$ \\
\hline $2002-03$ & 14,439 & $\$ 44,334$ & $35 \%$ \\
\hline $2001-02$ & 13,639 & $\$ 43,318$ & $33 \%$ \\
\hline $2000-01$ & 12,922 & $\$ 42,409$ & $32 \%$ \\
\hline $1990-91$ & 7,602 & $\$ 42,228$ & $31 \%$ \\
\hline $1980-81$ & 3,499 & $\$ 30,126$ & $25 \%$ \\
\hline
\end{tabular}

SOURCES:

http://nces.ed.gov/fastfacts/display.asp?id=76

http://www.census.gov/hhes/www/income/data/historical/household/

Keeping in mind the partially controversial evidence, we decided to test it using Data Envelopment Analysis (DEA). This allowed us weighing the labor force productivity, employment rate, and labor force participation against percentage of GDP spent on a college education and time spent in college. We analyze the dynamics of the college education from 1980 through 2010. Using DEA for the college efficiency efficiency estimations are known in literature, see, for example, publications [1, 4 - 5, 10 - 20, 23 - 25]. The mainstream of DEA applications is ranking colleges or the evaluation of college programs. In this setting, our research concerning the labor market perception of college education adds an additional dimension to this area of study.

The paper is organized as follows. Section 2 introduces a DEA model used in this research, and section 3 presents statistical data, obtained results, and their discussion. 


\section{Data Envelopment Analysis}

In his research we investigate how college preparation helps the improvement of the labor market. More specifically, we evaluate how money and time spent on college improve employed labor force productivity, employment rate, and participation. In other words, we indirectly evaluate the opportunity cost of time and money spent on college by computing the efficiency of college education in dynamics. While the positive impact of better education and training in general is beyond doubt for the vast majority of students and demonstrated by numerous studies in the literature, our goal is to find a quantitative measure of their effects. To achieve this goal, we compare the employed labor force productivity and participation, and employment rate to the college - related share of GDP and weighted average time spent in college. To do that, we weigh the first two indicators against the two last using the Data Envelopment Analysis (DEA) as a research tool.

DEA was invented in Charnes et. al. [6] by combining an efficiency ratio of Farrell [9] with a technique of transformation of a linear - fractional programming problem to the linear programming one Charnes \& Cooper [5]. DEA estimates the relative efficiency of a group of objects referred to as Decision-Making Units (DMUs) that use inputs $\mathbf{X}=\left(X_{j}, j=1, \ldots, r\right)>0$ to produce outputs $\mathbf{Y}=\left(Y_{i}, i=1, \ldots, s\right)>0$. DEA combines all the indicators of each object into an efficiency index $E$ scaled to an interval [0,1]. An object is considered efficient if it receives a score equal to 1 , and inefficient if it receives a score of less than 1 . The DEA efficiency measure is based on the efficiency ratio, [9]

$$
E=\frac{\sum_{i=1}^{s} u_{i} Y_{i}}{\sum_{j=1}^{r} v_{j} X_{j}}
$$

where $u=\left(u_{1}, \ldots, u_{s}\right) \geq 0$ and $v=\left(v_{1}, \ldots, v_{r}\right) \geq 0$ are the weights assigned to outputs and inputs, respectively.

To estimate the weights, the DEA sets up the following series of optimization problems: For each DMU $k, k=1, \ldots, N$, find vectors $u_{k}=\left(u_{k 1}, \ldots, u_{k s}\right) \geq 0$ and $v_{k}=\left(v_{k 1}, \ldots, v_{k r}\right) \geq 0$ that

\section{Maximize}




$$
E_{k}=\frac{\sum_{i=1}^{s} u_{k i} Y_{k i}}{\sum_{j=1}^{r} v_{k j} X_{k j}}
$$

subject to

$$
\sum_{j=1}^{r} v_{k j} X_{k j}=1
$$

and $E_{m} \leq 1$ for all $\mathrm{DMU}_{m}, m=1, \ldots, N$, in the group with the same weight coefficients $u_{k}=\left(u_{k 1}, \ldots\right.$, $\left.u_{k s}\right)$ and $v_{k}=\left(v_{k l}, \ldots, v_{k r}\right)$.

Conceptually, DEA ratio model (2) allows each DMU to assign the weight coefficients to each input and output favorably. However, the potential of a given DMU to achieve the maximum efficiency score is bound by the requirement that with the weight coefficients assigned to it, no other DMU in the group receives an efficiency score greater than 1 . This means that a poorly performing DMU cannot achieve a high efficiency score for itself through a manipulation of the weight coefficients. If this were the case, an object that performs really well would have received an efficiency score greater than 1 .

By using the findings of Charnes \& Cooper [5], publication Charnes et al. [6] showed that maximization of the efficiency ratio (2) is equivalent to solving a series of linear programming (LP) problems, one for each DMU in a group:

For each $\mathrm{DMU}_{k}, k=1, \ldots, N$,

Minimize $\theta$

subject to

$$
\begin{aligned}
& \sum_{m=0}^{N} \lambda_{k m} X_{m j} \leq \theta_{k} X_{k j}, j=1, \ldots, r ; \\
& \sum_{m=1}^{N} \lambda_{k m} Y_{m i} \geq Y_{k i}, i=1, \ldots, s ; \\
& \lambda_{k m} \geq 0, m=1, \ldots, N .
\end{aligned}
$$

The LP - algorithm given by the formulas (3) forms a linear combination of DMUs that outperforms the currently selected DMU by both inputs and outputs. 
Formulas (2) and (3) define ratio and envelope DEA models, respectively. The output minimization (OM) ratio DEA model (2) is dual to the envelope input minimization (IM) DEA model (3) with weight coefficients $u_{k j}$ and $v_{k j}$ being the multipliers. The efficiency scores provided by both OM and IM models are equal to each other. Both models are of the "constant returns to scale" (CRS) type: The efficiency scores remain the same if the units of measurement of inputs or outputs change, or if one or several indicators change proportionally due to inexactness in a measurement, see [6] and [26] for detail.

In the envelope model (3), at the point of minimum, only those $\lambda_{\mathrm{km}}$ are non - zero that correspond to the efficient $\mathrm{DMU}_{m}, m=1, \ldots, N$; not necessarily all of them. Some of the weight coefficients $u_{k j}$ and $v_{k j}$ in the ratio DEA model (2) may be zero at the point of maximum. This means that some outputs or inputs are not crucial and may be decreased or increased, respectively, without change in the efficiency scores. Publications $[7,26]$ provide details and reviews of contemporary DEA.

For the objectives of this research, the ratio is used in the statement of the optimization problem, while the envelope model serves as a computational means.

\section{College education efficiency modeling and analysis}

To construct a model of the college education efficiency, we used the employed labor force productivity, employment rate, and labor force participation indicators as outputs, and Percentage of GDP spent on a college education and weighted time spent on college preparation, as inputs. Statistical data on the nominal and real GDP are available on the website of the Bureau of Economic Analysis [27], on the labor force and labor force participation - on the website of the Bureau of Labor Statistics [28]. The Employed labor force productivity indicator was calculated as a ratio of the real GDP expressed in chain 2005 dollars to the employed labor force. Statistical data regarding the share of GDP spent on college education was obtained as a ratio of the expenditures by all postsecondary degree-granting institutions to the nominal GDP. The expenditure component (the numerator) of this ratio was obtained from the website [29] of the National center for educational statistics (NCES). To estimate the duration of college preparation, we used statistics available on the [29]. It provides two indicators: Percentage of the civilian labor force age 25 to 64 having 1 to 3 years of college, and 4 years or more. We used this 
information to calculate an average duration of college by taking the mid-value of 2 years for the first category and 5 years for the second. Although this approach gives only a rough approximation of the college duration, the error does not affect the efficiency score dramatically because the DEA model used in this research is indifferent to the proportional change in the indicators. By doing so, we received DEA inputs and outputs shown in columns 2 - 6 of table 2 and figure 1.

Efficiency scores were calculated by using DEA model (3). They are shown in column 7 of table 2 and in figure 2. They reveal that fully efficient were the years 1980, 1981, 1998, 1999, 2005, 2006, and 2010. Some of them appeared as peer DMUs with particular $\lambda$ - values. By weighing the inputs corresponding to the fully efficient years by the $\lambda$ - values, we received that $2.52 \%$ of GDP spent on a college education and 1.84 years of college study may be considered as optimal for this period.

The efficiencies of other years were in the range of $93.5 \%-97.7 \%$. It should be stressed that DEA evaluates relative efficiency only, so that so high efficiency scores are just relative values. DEA assigns zero weights to some inputs or outputs that means that the efficiency score will not be changed if their values are slightly decreasing or increase. By counting the non - zero weight coefficients for the college - related inputs, we obtained 29 cases for the percentage of

Table 2. DEA inputs and outputs, efficiency, and business cycles

\begin{tabular}{|c|c|c|c|c|c|c|c|}
\hline Year & $\begin{array}{c}\text { Employed } \\
\text { labor force } \\
\text { productivity, } \\
\$ 2005\end{array}$ & $\begin{array}{l}\text { Employment } \\
\text { rate, \% }\end{array}$ & $\begin{array}{c}\text { Labor force } \\
\text { participation, } \\
\qquad \%\end{array}$ & $\begin{array}{c}\text { Spending } \\
\text { on college, } \\
\% \text { GDP }\end{array}$ & $\begin{array}{c}\text { Years } \\
\text { of } \\
\text { college }\end{array}$ & $\begin{array}{c}\text { Efficiency, } \\
\%\end{array}$ & $\begin{array}{c}\text { Business } \\
\text { Cycle }^{1)}\end{array}$ \\
\hline (1) & $(2)$ & (3) & (4) & (5) & (6) & (7) & (8) \\
\hline 1980 & 58749 & 92.9 & 63.8 & 2.30 & 1.45 & 100.0 & 93.0 \\
\hline 1981 & 59584 & 92.4 & 63.9 & 2.25 & 1.45 & 100.0 & 100.0 \\
\hline 1982 & 58938 & 90.3 & 64.0 & 2.33 & 1.50 & 96.8 & 93.0 \\
\hline 1983 & 60802 & 90.4 & 64.0 & 2.32 & 1.57 & 97.5 & 93.9 \\
\hline 1984 & 62583 & 92.5 & 64.4 & 2.29 & 1.60 & 99.9 & 94.8 \\
\hline 1985 & 63867 & 92.8 & 64.8 & 2.31 & 1.63 & 100.0 & 95.6 \\
\hline 1986 & 64605 & 93.0 & 65.3 & 2.37 & 1.63 & 98.3 & 96.5 \\
\hline 1987 & 64986 & 93.8 & 65.6 & 2.40 & 1.66 & 97.5 & 97.4 \\
\hline 1988 & 66170 & 94.5 & 65.9 & 2.43 & 1.68 & 97.3 & 98.3 \\
\hline 1989 & 67147 & 94.7 & 66.5 & 2.46 & 1.72 & 96.9 & 99.1 \\
\hline 1990 & 67572 & 94.4 & 66.5 & 2.52 & 1.73 & 95.8 & 100.0 \\
\hline 1991 & 68030 & 93.2 & 66.2 & 2.61 & 1.75 & 94.6 & 93.0 \\
\hline 1992 & 69878 & 92.5 & 66.4 & 2.61 & 1.82 & 94.1 & 93.7 \\
\hline 1993 & 70815 & 93.1 & 66.3 & 2.60 & 1.88 & 93.5 & 94.4 \\
\hline 1994 & 72023 & 93.9 & 66.6 & 2.58 & 1.92 & 94.2 & 95.1 \\
\hline 1995 & 72746 & 94.4 & 66.6 & 2.57 & 1.97 & 94.6 & 95.8 \\
\hline 1996 & 74390 & 94.6 & 66.8 & 2.55 & 1.98 & 96.1 & 96.5 \\
\hline 1997 & 75996 & 95.1 & 67.1 & 2.51 & 1.98 & 98.5 & 97.2 \\
\hline 1998 & 78157 & 95.5 & 67.1 & 2.49 & 2.00 & 100.0 & 97.9 \\
\hline 1999 & 80687 & 95.8 & 67.1 & 2.53 & 2.05 & 100.0 & 98.6 \\
\hline 2000 & 81937 & 96.0 & 67.1 & 2.61 & 2.08 & 99.1 & 99.3 \\
\hline
\end{tabular}




\begin{tabular}{|c|c|c|c|c|c|c|c|}
\hline 2001 & 82796 & 95.3 & 66.8 & 2.73 & 2.10 & 97.4 & 100.0 \\
\hline 2002 & 84574 & 94.2 & 66.6 & 2.85 & 2.13 & 96.7 & 93.0 \\
\hline 2003 & 85935 & 94.0 & 66.2 & 2.84 & 2.15 & 97.4 & 94.4 \\
\hline 2004 & 87948 & 94.5 & 66.0 & 2.83 & 2.18 & 98.3 & 95.8 \\
\hline 2005 & 89064 & 94.9 & 66.0 & 2.80 & 2.17 & 100.0 & 97.2 \\
\hline 2006 & 89724 & 95.4 & 66.2 & 2.81 & 2.19 & 100.0 & 98.6 \\
\hline 2007 & 90426 & 95.4 & 66.0 & 2.91 & 2.23 & 98.8 & 100.0 \\
\hline 2008 & 90546 & 94.2 & 66.0 & 3.01 & 2.28 & 96.7 & 96.5 \\
\hline 2009 & 91208 & 90.7 & 65.4 & 3.20 & 2.27 & 97.5 & 93.0 \\
\hline 2010 & 93935 & 90.4 & 64.7 & 3.17 & 2.28 & 100.0 & - \\
\hline Min & 58749 & 90.3 & 63.8 & 2.25 & 1.45 & 93.5 & \\
\hline $\operatorname{Max}$ & 93935 & 96.0 & 67.1 & 3.20 & 2.28 & 100.0 & \\
\hline Average & 75026 & 93.7 & 65.9 & 2.61 & 1.90 & 97.7 & \\
\hline
\end{tabular}

Note

1) The peaks and troughs years are obtained from http://nber.org. Their values are taken as $100 \%$ and $93 \%$, respectively for the correlation calculations and are italicized. Other values are interpolated.

GDP spent for college education and 22 cases for the time spent in college. The difference obtained in this research is not statistically significant (p-value is 6.9\%), but, if confirmed in a broader study, might be interpreted as a greater value of college spendings with regard to the time of college study. In other words, college education would be more efficient if made cheaper than made equally more intensive to shorten the college time.

Statistical analysis of the efficiency scores dynamics did not reveal statistically significant trends. The regression coefficient of the efficiency versus time is $b=0.1077, p$-value $=67.16 \%$, much more than the standard 5\%. Based on this observation, we could claim that on average the efficiency of college education remained unchanged during the period of study. At the same

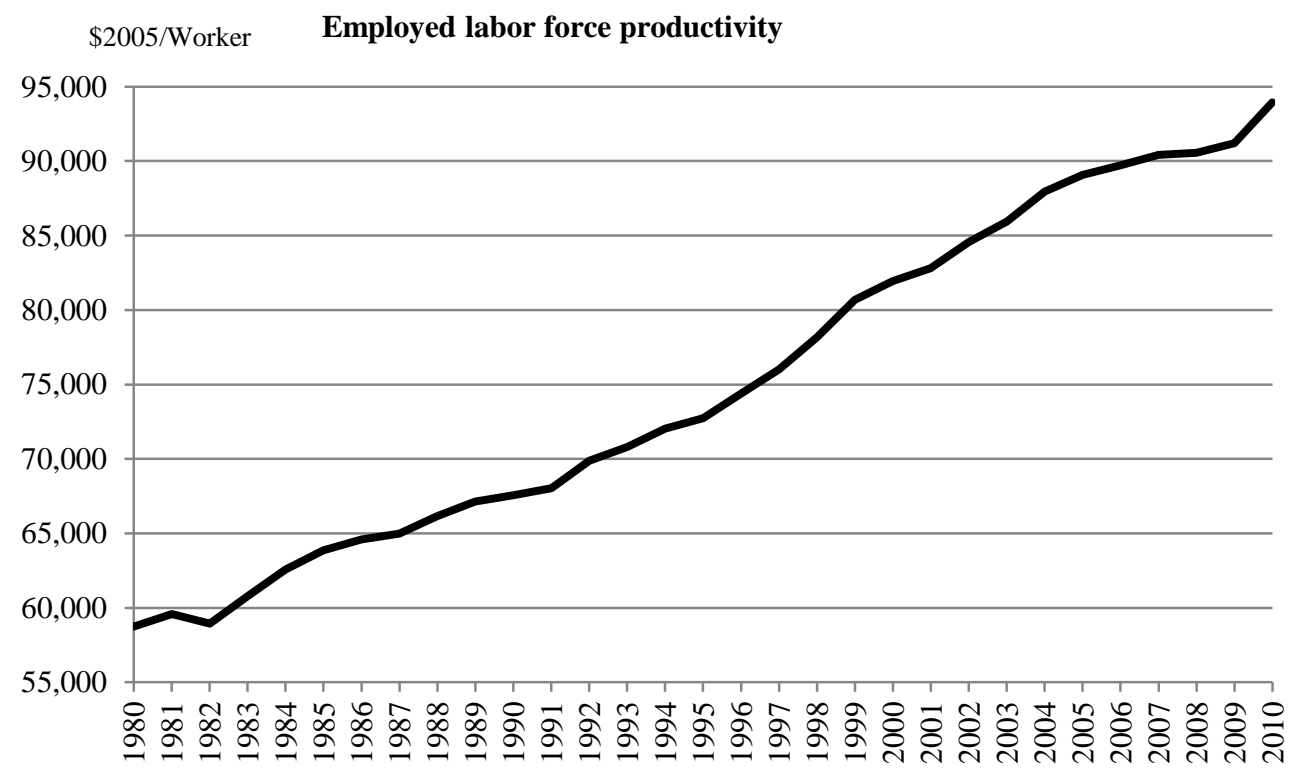

a) Employed labor force productivity, Output - 1 


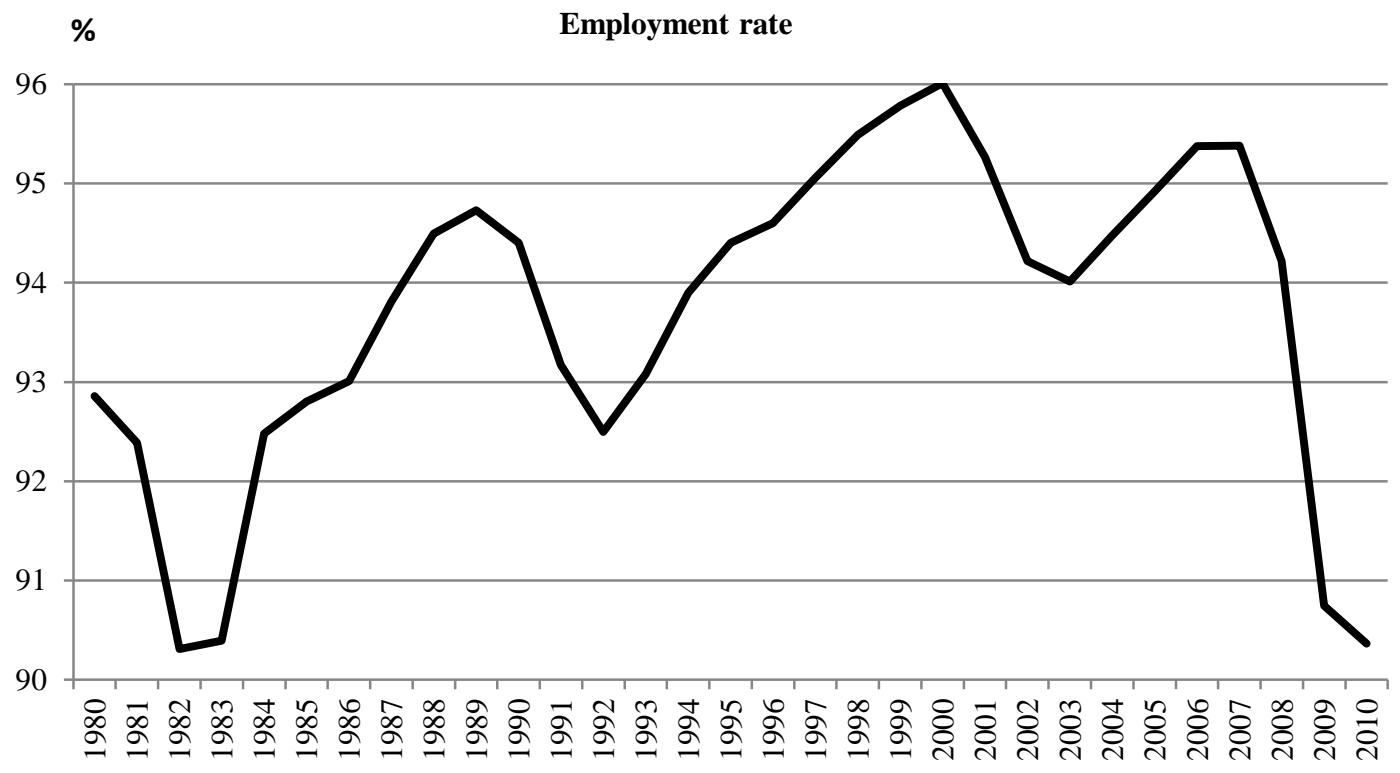

b) Employment rate, Output - 2

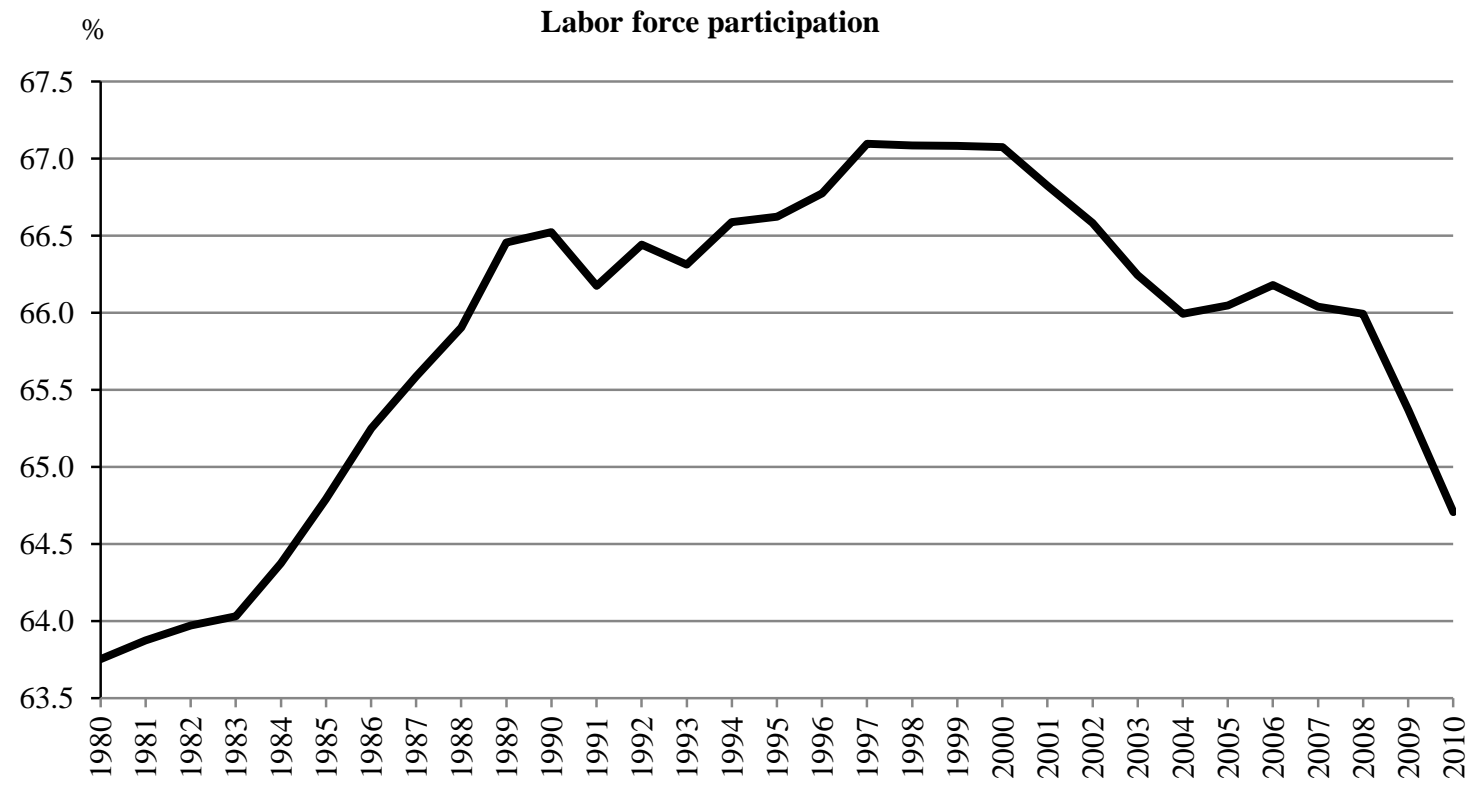

c) Labor force participation, Output - 3 


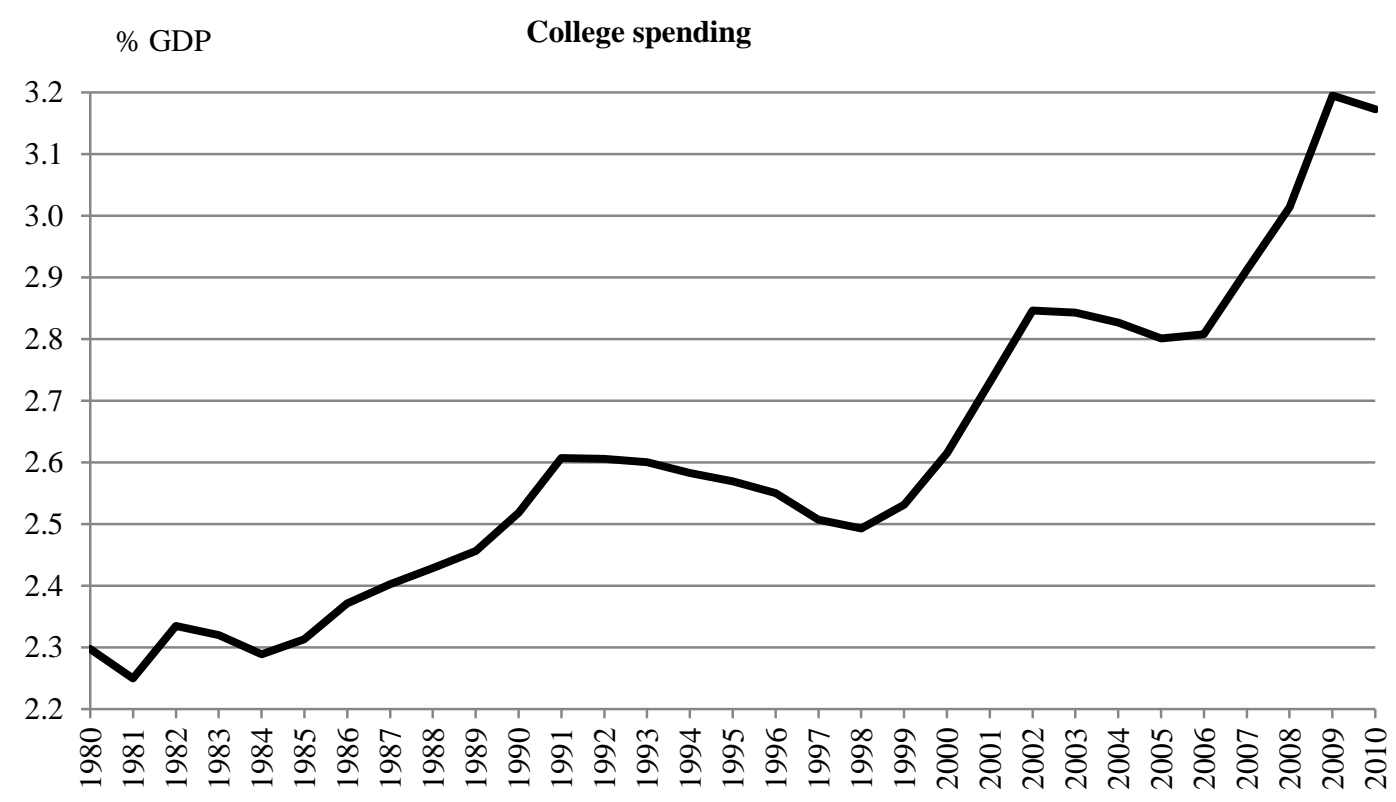

d) Spending on college, Input - 1

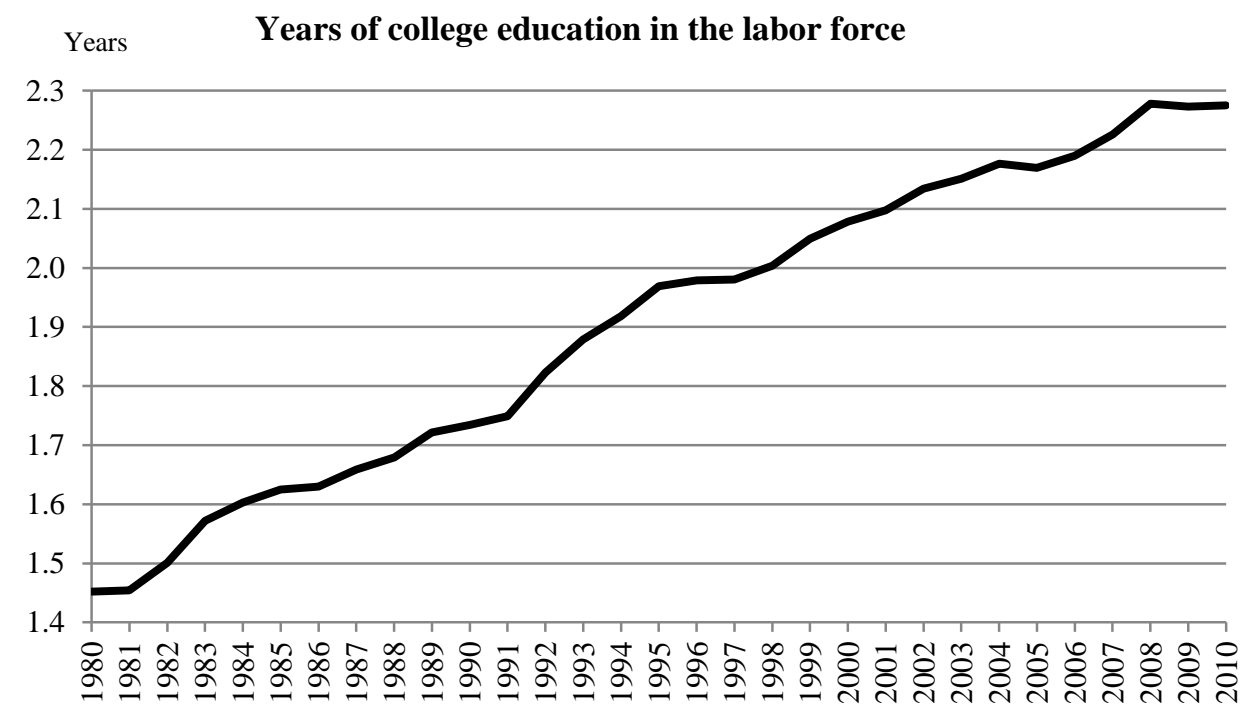

e) Years of college education, Input - 2

Fig. 1. DEA inputs and outputs in dynamics

time, there are clearly visible cycles in the figure 2 . We assumed that business cycles may be the reason of this cyclicity. To test this hypothesis, we used information of the National Bureau of Economic Research (NBER) available on the website [30]. This website provides data on the 
peaks and troughs of the business cycles. Since the objective of this research was to investigate the correlation between the business cycles and the cycles of college efficiency scores, the numerical values of the peaks or troughs were not of any importance. For the convenience of graphical presentation, we assigned the $100 \%$ value to the peaks, and $93 \%$ - just below the minimal DEA efficiency score - to the troughs, and connected them by line segments. (Using any other peak - trough range would not affect the correlation coefficient between the dynamics of efficiency score and peak-trough cycles.) The business cycles piecewise curve obtained in this way is shown in column 8 of the table 2 and in figure 2. Statistical analysis revealed that the correlation coefficient $(R=0.4718)$ is statistically significant at $1 \%$ level $(F=0.0098)$ and is greatest when the efficiency scores are taken with a lag of one year. This observation sugguests that the college - trained part of the labor force has more volatile labor market experience during business cycles than other parts of the labor force Unexpectedly we find that college - educated lose jobs even when the downturn of the economy.

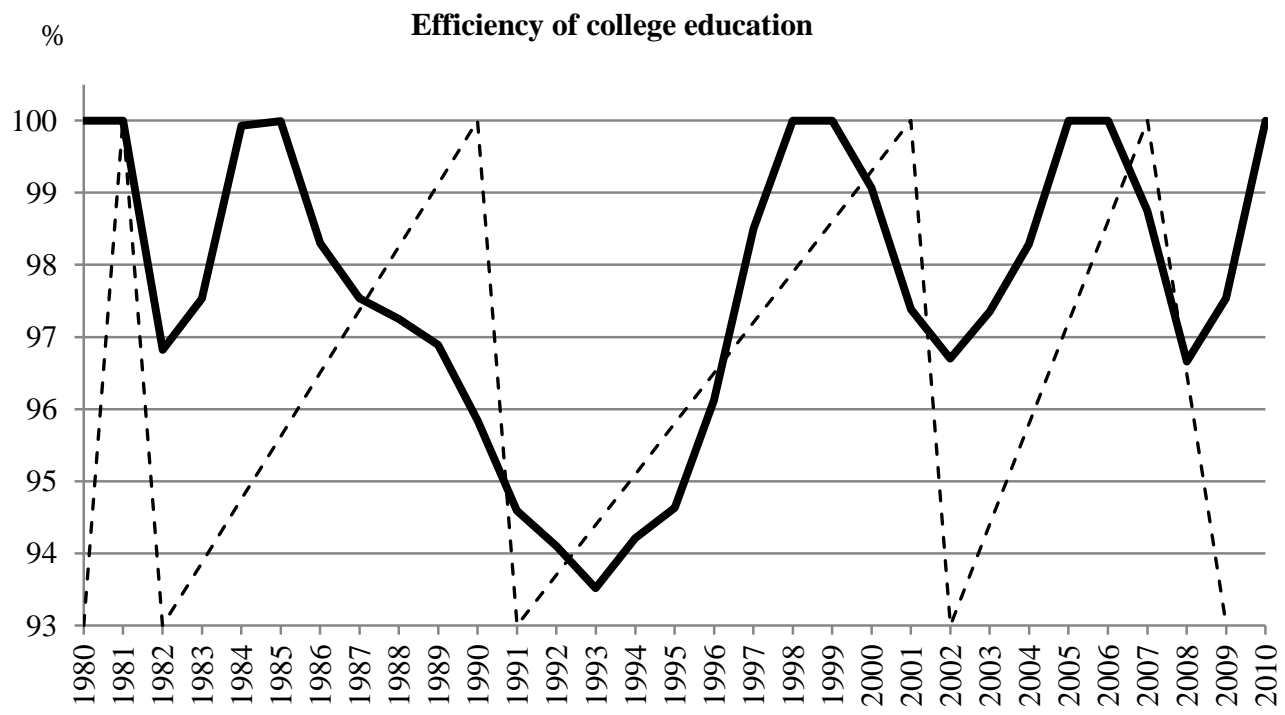

Fig. 2. Efficiency of college education and business cycles Efficiency scores Business cycles 
Our result suggests that firms may carry highly skilled workers "in inventory" and the layoffs of highly skilled workers are less costly than goods inventory changes. At the same time, they enjoy the economic growth before it actually begins. Topel [22] argues that "There are important structural differences among industries in short-run employment, hours, and inventory decisions." Using Topel's ideas our work here, suggest that recently firms have found it less expensive to inventory high skilled labor as opposed to goods. This may have been the result of “just in time" goods production with virtually no inventories of goods. Publication [8] partially supports our opinion and shows that such situation takes place in contemporary China.

\section{Conclusions}

The paper investigates to what extent financial resources and time spent on college education are justified by an increase in the productivity, employment, and the labor force participation in the United States labor market. The evaluation was obtained by constructing a DEA efficiency index that weighed the employed labor force productivity, employment rates, and labor force participation against a college - related share of GDP and weighted time spent by the labor force on college study for the period of 1980 - 2010. The obtained results revealed that the efficiency index had no statistically significant trend but was correlated with the business cycles with a lag of one year. The latter observation underlines an assumption that the college trained part of the labor force is more volatile with regards to the business cycles. It loses jobs faster at the very beginning of the downward sloping stage of the business cycle and gains quicker when the upward phase of the cycle begins Parameters of the fully efficient years allowed for the estimates of the optimal values of the share of GDP and the duration of college preparation.

\section{Acknowledgment}

The authors are thankful to Aurora D'Amico from the National Center for Education Statistics and Vernon Brundage Jr. from the Bureau of Labor Statistics for assistance in the collection of statistical data for this research.

\section{References}


[1] Ahn, T., Charnes, A., Cooper, W. (1988). Some statistical and DEA evaluations of relative efficiencies of public and private institutions of higher learning. Socio-Economic Planning Sciences, 22 (6), 259-269.

[2] Bennett, W., Wilezol, D. (2013). Is college worth it? Thomas Nelson.

[3] Brown, J., Fang, C, and Gomes, F. (2012). Risk and Returns to Education. National Bureau of Economic Research, Working Paper \#3838. Available at http://www.nber.org/papers/w18300.

[4] Chang, D., and Tsai, P. (2013). The effect of industry-academy cooperation explained by data envelopment analysis. ICIC Express Letters, 7 (1), 79-84.

[5] Charnes, A., Cooper, W., (1962). Programming with linear fractional functionals. Naval Research Logistics Quarterly, 9, 181 - 186.

[6] Charnes, A., Cooper, W. W., \& Rhodes, E. (1978). Measuring the efficiency of decisionmaking units. European Journal of Operational Research, 2, 429-444.

[7] Cooper, W., Seiford, L., \& Zhu, J. (Eds.) (2011). Handbook on Data Envelopment Analysis (International Series in Operations Research \& Management Science), 2nd. ed., Springer.

[8] Davis, B. (2013). Chinese college graduates play it safe and lose out. The Wall Street Journal, March 26, A1.

[9] Farrell, M. J. (1957). The measurement of production efficiency. Journal of the Royal Statistical Society, Series A, 120 (3), 253-282.

[10] Fu, T., and Huang, M. (2009). Performance ranking and management efficiency in colleges of business: A study at the department level in Taiwanese universities. Contributions to Economics, 197-215.

[11] Guo-Yuan, H. (2011). Research on efficiency evaluation of university technological innovation in Heilongjiang province. International Conference on Management Science and Engineering - Annual Conference Proceedings, \#6070088, 1060-1066.

[12] Hatch, M., Noble, C., and Wooton, S. (2002). College ranking - You be the judge. Proceedings - Annual Meeting of the Decision Sciences Institute, 2077-2082.

[13] Hidalgo-Hidalgo, M., Iturbe-Ormaetxe, I. (2012) Should we transfer resources from college to basic education? Journal of Economics/ Zeitschrift fur Nationalokonomie, 105 (1), 1-27. 
[14] Jianhua, S. (2010). The evaluation of college Education Science and Technology innovation performance based on data envelopment analysis. ICEIT 2010 - 2010 International Conference on Educational and Information Technology, Proceedings, 2, \#5608441, V259-V263.

[15] Kao, C. (1994). Evaluation of junior colleges of technology: The Taiwan case. European Journal of Operational Research, 72 (1), 43-51.

[16] Kong, W., and Fu, T. (2012). Assessing the performance of business colleges in Taiwan using data envelopment analysis and student based value-added performance indicators. Omega, 40 (5), 541-549.

[17] Mincer, J. (1991) Education and Unemployment. National Bureau of Economic Research, Working Paper \#3838. Available at http://papers.nber.org/tmp/40331w3838.pdf

[18] Said, A. (2011). Assessing the efficiency of for profit colleges and universities during the period of 2005-2009. International Research Journal of Finance and Economics, 70, 90128.

[19] Shih, C. (2012). The effects of governmental subsidy on the quality of education in Taiwan's private universities and colleges. Lecture Notes in Computer Science, 7513 LNCS, 373-380.

[20] Sui, Y., Li, G., and Zhang, X. (2011). Cost-effectiveness evaluation of IHEs based on grey relation analysis with weights by DEA Model. Proceedings of 2011 IEEE International Conference on Grey Systems and Intelligent Services, GSIS'11, \#6043983, 154-158.

[21] The Economist (2012). United States. Higher Education. Not what it used to be. American universities represent declining value for money to their students. December $1^{\text {st }}$ 2012. Available at http://www.economist.com/printedition/2012-12-01.

[22] Topel, Robert, H. "Inventories, Layoffs, and the Short-Run Demand for Labor", The American Economic Review, Vol. 72, No. 4 (Sep., 1982), pp. 769-787.

[23] Xiao-Hong, Z. (2011). Evaluation and analysis on benefit of Chinese college resources input. Lecture Notes in Electrical Engineering, 111 LNEE, 267-272.

[24] Xie, N., and Xiao, J. (2009). The efficiency evaluation of the college which based on DEA. Proceedings of the 1st International Workshop on Education Technology and Computer Science, ETCS 2009, 1, \#4958749, 168-172.

[25] Zhu, X. (2011). Evaluation and analysis on benefit of college resources input of China. Advanced Materials Research, 328-330, 2358-2361. 
Web sites

[26] http://deazone.com

[27] www.bea.gov

[28] www.bls.gov

[29] http://nces.ed.gov/about/

[30] http://nber.org

[31] http://nces.ed.gov/ fastfacts/display.asp?id=76
DEA website

Website of the U.S. Bureau of Economic Analysis Website of the U.S. Bureau of Labor Statistics.

Website of the U.S. National Center for Educational Statistics.

Website of the U.S. National Bureau of Economic Research.

Website of the Department of Education U.S. National Center for Educational Statistics.

Website of the US Bureau of the Census www/income/data/historical/household/ 


\section{Bios}

William Alpert joined the Economics Faculty of the University of Connecticut in the fall of 1983 and was promoted to Associate Professor of Economics (with tenure) in 1987. He publishes widely in his field of labor economics, including work on nonwage compensation, the minimum wage, economic and financial literacy and transitional economies. His research has received attention both among academics and in the public policy arena. He has, for example, been called upon to discuss his research on family and medical leave on the Today Show and several other television and radio programs. His work has also been cited in major publications including The Washington Post, The Chicago Tribune, The New York Times, and The Wall Street Journal. He is widely consulted by both print and broadcast journalists on a wide variety of economic questions. He serves as Executive Director of the Connecticut Council on Economic Education and has served as Director of the Center for Economic Education at the University of Connecticut. He serves on several not-for-profit boards of directors usually as Secretary/Treasurer.

Prior to his appointment at the University of Connecticut Mr. Alpert taught at Lehigh University (1981-83), Washington University, St. Louis, (1977-81), and Columbia University (1973-77). Prior to his appointment at the University of Connecticut Mr. Alpert directed a successful academic center and developed several university programs.

Mr. Alpert is partner and co-founder of Fides Philanthropic Management in 1997, was Senior Program Officer of the William H. Donner Foundation from 1987 until 1999.

Mr. Alpert served as associate producer of several television programs, including Firing Line. He has testified before legislative bodies at the state and local levels, was a founding member and, second chairman of the Water Pollution Control Authority in Bridgeport, CT and is currently a member of the CT State Advisory Commission to the U.S. Commission on Civil Rights. Mr. Alpert earned his Ph.D. M. Phil. and MA degrees in Economics from Columbia University and his $\mathrm{AB}$ from Lehigh University.

Alexander Vaninsky is currently a Professor of Mathematics at Hostos Community College of the City University of New York. He received his master's degree in electrical engineering from the Moscow Power Engineering Insitute, in mathematics - from Moscow State University, and Ph.D. and D. Sc. Degrees in mathematical economics - from Moscow Finance University. Author and co-author of five monographs and over 30 articles. Recipient of different grants and awards; among them - Stephen J. Shaw Award for Most Outstanding Paper (Irwin Publishing, USA) His current research focuses on the development and applications of new methods of economic analysis. 